\title{
Decolonization, development and disease: a social history of malaria in Sri Lanka by Kalinga Tudor Silva. (Orient Black Swan, 2014)
}

\section{A social history of malaria in Sri Lanka}

\author{
Reviewed by Laksiri Fernando* \\ Former Senior Professor, Department of Political Science and Public Policy, Faculty of Arts, University of Colombo, Colombo.
}

\begin{abstract}
'Disease' is not merely a medical issue; it is a social phenomenon intercepted by power, politics, political economy, culture, language, religion and historical forces, not to speak of ecology or geography. This is the main perspective of Kalinga Tudor Silva's path breaking study on A social history of malaria in Sri Lanka, published by Orient Black Swan in 2014.The argument has a Foucauldian connotation after Michel Foucault's much famed study Madness and civilization (1967). Spanning into 258 pages with tightly knit and logically ordered seven chapters, the book is an in-depth study of the malaria epidemic in Sri Lanka for over 80 years from early 1930s to the present day, both covering the colonial and postcolonial dimensions of this deadly disease and its socio-economic and political ramifications.
\end{abstract}

This intensive analysis, following the best traditions of research methodologies of interdisciplinary sociology, places the in-depth empirical investigations and material (18 tables, 7 figures and 9 maps), including its field research, within a universally acceptable theoretical and a historical framework for any discerning reader to understand the main theses or the respective arguments in a logical manner. Although not completely free from controversy or debate, the author appears to counter or question the tropical medicine thesis that malaria is a permanent 'tropical disease with a firm foundation in a fixed tropical environment.' Instead, the author in his own words, highlights the case of Sri Lanka,

"significance of human interventions, such as social and environmental changes brought about by plantation development under colonialism and economic development, migration and war under postcolonial regimes in the transmission and control of epidemic malaria in particular"

\section{APPROACHES AND QUESTIONS}

The author in his theoretical introduction to the analysis has delineated three different approaches to the study of man's struggle against malaria initially in the colonial period yet continuing in the postcolonial contexts in many countries. First is the approach of what he has called the 'modernist approach' which is apolitical (or pretends to be) and attempts to be purely 'scientific,' based on modern science and scientific research on disease and medicine. The weakness of this approach might be not only the neglect of traditional knowledge in the respective countries but also the evolving social and environmental conditions. The second approach is the 'history of colonial medicine' which deviates from the apolitical modernist approach but infuses a colonial objective into malaria control, treating the indigenous people as 'the other' or a 'subject species' with several required social and political policies in malaria control. Emergence of tropical medicine is partly a product of this approach. This was also in a sense the 'White Man's Burden'. The work of Arnold (1993) often explains this approach.

More enlightened perhaps is the third approach or the 'socio-historical perspective' developed by McNeill in his Plagues and People (2008) which takes not only

\footnotetext{
1. As Rudyard Kipling (1899) said, "Take up the White Man's burden, The savage wars of peace, Fill full the mouth of Famine, And bid the sickness cease, And when your goal is nearest, The end of others sought, Watch sloth and heathen folly, Bring all your hopes to nought."
} 
people's concerns but also their traditional methods in combating diseases like malaria. Silva's analysis in a sense is an extension of this third approach with several distinct features. The author does not confine himself to the above three approaches restrictively and instead invokes and employs a variety of other perspectives and positions such as,

\section{"development discourse, ethnography, nationalism, critique of western hegemonic control over science and technology, marginalisation of indigenous knowledge systems including herbal medicine and a larger and a more insidious process of colonisation of the mind."}

It is important to underline at the outset that the author's treatment of nationalism in this context is constructively critical which emphasises on the one hand nationalism's positive critique of colonialism and on the other it's regressive role in promoting ethnic dominance, conflict or armed interventions. The latter is the reason for his extensive analysis of the 'War-induced malaria outbreak in northern Sri Lanka, 1990 to 2002' in Chapter 5.

The author has raised five clusters of research questions for his field research and historical investigation and explication in the book. (1)What was the nature of accumulated knowledge about fevers and cultural adaptation to the malaria disease in dry zone Sri Lanka and how was it affected by advances in western medicine in general and malariology in particular? (2) What were the historical and social roots of the malaria epidemic in 1934/35 and what were the short term and long term negative and positive consequences in terms of policies, structural adaptations and political movements? (3) How did the developmental push of the Sri Lanka state, particularly after independence, interact and intersect with malaria transmission in postcolonial era and pose new challenges for the control of the disease? Or in other words, how did the discourse of malaria eradication interact with the development discourse? (4) How did the devastating civil war (1983-2009) impact on disease transmission and pose new challenges associated with human hostilities, loss of life, forced migration and massive devastation of infrastructure including health? (5) More pertinently, what are the overall implications of more historically grounded understanding of the social factors affecting the transmission and control of malaria for future policies and programmes in Sri Lanka?.

\section{DISCOURSES ON MALARIA}

Foucault (as cited in Barry \& Yuill, 2002) argued that in order to understand medicine or disease, they have to be thought of as 'discourses' of health, rather than accepting them merely as objective descriptions of reality. This is particularly true in the case of colonial medicine or tropical medicine. Beginning by 'Mapping fevers in British Ceylon'(Chapter 1), this is what Silva has exactly done in his book. If a reader intends to follow the author along the research questions that he has posed in the introduction, there can be a disappointment. Nevertheless, the chapter order makes sense although the author has not posed the discourse analysis as a specific research question/s.

For the Portuguese, Dutch and early British records, all were 'agues and fevers' and the scientific discovery of malaria came rather late in $1880^{2}$. For Robert Knox it was 'country sickness' and for the Sinhalese it was largely Kala Una (forest fever). The reasons given were various and it was curious that Emerson Tennent in 1858 both used the term 'malaria' and identified the culprit as "mosquito" 3 . In this chapter, while the author gives a comparative picture with India or particularly Bengal and Gujarat, he also takes the discourse back to ancient civilisations of Sri Lanka (Anuradhapura and Polonnaruwa). The theory put forward by Nicolls (1921) that malaria was introduced to Ceylon from South India that caused the fall of the ancient cities is speculative and as the author has underlined clearly, the theory also reinforced Sinhala nationalism with the advent of malaria in 1930s.

It is pertinent that the author has investigated, in Chapter 2, how peasants in the malaria endemic regions in the dry zone perceived and dealt with malaria prior to the introduction of tropical medicine and DDT and what effects these new technologies have had on the pre-existing ideas and practices. The results presented here are based on the author's previous study on ethnohistory of malaria as part of the Sarvodaya Malaria Control Research Project from 1983 to 1986 (Silva et al., 1988). It is not clear, however, to what extent people's superstitions or folk myths were mixed up with the indigenous understanding of malaria, its spread and possible control. There was also a distinction between indigenous medicine (Ayurveda) and folk understanding. However, there was overwhelming antipathy suspecting

2 There are two claimants for the discovery, Charles Laveran (French) and Donald Ross (British), but the latter is of more credit because of his identification of Anopheles as the villain in human malaria (Marcus 2004).

It is possible that Tennent by that time had read An inquiry into the origin and intimate nature of malaria by Thomas Wilson (1858). 
the intrusion of western medicine. As a herbal practitioner has remarked "malaria was first introduced to the area with the introduction of DDT!"

As the author says, the peasants in the area,

"had a clear concept of periodicity and seasonality of fevers, and their association with rainfall patterns and seasonal changes in vegetation... They also had a rich herbal pharmacopoeia for dealing with different types of fevers and related complications."

Although mosquito was not recognised as a disease vector by the local people, mosquito repellent or control was considered important at least as preventing a nuisance. There are much more in the chapter and what it might prove is what an enlightened British Governor, Henry Blake, stated in 1905 to "recognize the importance of indigenous knowledge in eradication of malaria in the country" (as cited in Uragoda, 1987).

Malaria epidemic during 1934-35 brought the disease and politics closer together. Chapter 3 titled 'Mixing politics with Quinine' tells the story of this synergy. Malaria was not only a health issue but primarily a political one. Granting of universal franchise in 1931 heightened its political potential or character. The epidemic took 80,000 to 100,000 lives or nearly 2 percent of the population. More people became ill. It was a challenge for malariology and tropical medicine, like Ebola today. As the author says, the 'official discourse' attributed the epidemic primarily to climatological and environmental factors. The author outlines the 'scientific discourse' as well, which gave emphasis on increasing deficiency in immunity among certain vulnerable sections of the population midst other factors. What was missing in both discourses was left for politics or public media to cover. The author records interesting episodes reported by the media and one story depicts the picture of "a man ill with fever having to carry the dead body of his child in one hand and a mamoty in the other in order to bury the child." Then there is the incredible story uttered by a politician, of a doctor in Kurunegala who had seen 5,000 patients in five days!

This is the best chapter in a sociological sense in Silva's book on malaria. However, it has to be noted that in his analysis of particularly the political responses to the disaster, the fundamental differences between the nationalists and the Leftists have not been clearly identified by the author as much as it should have been. It is well known that some of the nationalist leaders were lukewarm or reluctant at the beginning in addressing the issue. Some even used to attribute the epidemic to karma (Vijayawardhana, 1953). It was basically the Left leaders who clearly identified the link between wasangathaya (the epidemic) and sagathaya (hunger) which became a prominent social discourse on the subject thereafter.

\section{POSTCOLONIAL SCENARIO}

There is no question that the shock waves created by malaria and the political responses to that calamity helped shape the welfare state in Sri Lanka among other developments. The main cry was for universal health and free education.There were however weaknesses in the thesis that 'malaria blocks development' and therefore, 'eradication of malaria unblocks development.' This is a problematique that the author has investigated critically in his subsequent chapters. In the author's view, the sustainability of malaria eradication largely depended on the particular path/s that development followed after independence. Malaria was a primary cause of underdevelopment and poverty in the dry zone. Malaria eradication unblocked the difficulties in developing colonisation schemes which was basically a prominent political project of Sinhala nationalism. However, there were obvious defects in the new irrigation schemes. As the author says,

"Irrigation development resulting in humanmade vector-breeding sites and related settlement programmes involving the movement of people from malaria non-endemic regions to malaria endemic regions were at least partly responsible for the resurgence of malaria in Sri Lanka since 1967."

The most fascinating chapter of the book perhaps is "War-induced malaria outbreak in northern Sri Lanka, 1990-2002'. The analysis is both theoretical and empirical. Wars have played a significant role in the historical epidemiology of malaria throughout the world and as the author says, "sometimes killing more soldiers by malaria than in actual combat operations!" Therefore, peace is a necessary condition. The chapter gives a global picture, while going in depth into what happened in northern and eastern Sri Lanka during the war period. As Table 5.1 in the book shows, the positive number of cases in the two provinces have increased exponentially with associated deaths during 1996 and 2000. This corresponds very clearly with the Third Eelam War (1995-2001) in the country. The Jaffna district which was relatively free from Malaria even during the worst periods previously, as the author has demonstrated, was the first to succumb to the disease in early 1990s. Rapid population movement, human displacement and the breakdown of health and medical infrastructure were at 
the heart of the outbreak. Undoubtedly, malaria was a minor worry for the people and the health workers during the war, faced with terror, bombing or combat fighting. In an interview conducted by the author,

"a university lecturer from Jaffna who had spent four years as a displaced young person from Jaffna in Kilinochchi between 1996 and 2000 had mentioned that he was infected with malaria four times during this period."

\section{CONCLUSION}

The social discourse on malaria has changed over time, from colonial to postcolonial, with variations within each period. It is questionable however whether the issue of malaria or malariology is a discourse alone. That is not the argument of the author either. The physical, biological or technological conditions of malaria or malariology also have changed, but those are not necessarily related to people's perceptions or hegemonic interests formulated into discourses. Although overlapping, the distinction between a discourse and a science doesn't need to be overstated. The author has primarily dealt with the discourse side of the issue but has never denied science, natural or social.

The indigenous criticisms against western medicine or tropical medicine on malaria emanate not only from the perceptions but also from the traditional (experiential and experimental) knowledge akin to science today. Ayurveda, Yunani or Siddha are not mere discourses but Vidya (science or scientific knowledge), however imperfect, largely disrupted by colonial and other interferences. An associated problem particularly with tropical medicine and malariology may be the influence of the multinational pharmaceutical and chemical corporations.

There are four major historical continuities and discontinuities that the author has highlighted in concluding the study which may appear arbitrary to summarise, nevertheless useful in a review. (1) Malaria has erupted cyclically or in waves. Unfortunately, at the end of each wave there was considerable optimism among the malaria workers, general public and the policy makers. The author warns us against this irrational optimism; (2) Malaria has rejuvenated after each wave, bypassing the existing knowledge, technology, strategies and malariology. Another reason for the holding back of our knowledge is the undue dominance of prevailing ideologies or institutions both nationally and globally.
The requirement is continuous critical research; (3) The importance of environmental protection in general is paramount. As malaria epidemics have underpinned, most of these disasters are related to environmental denigration and/or ecological changes as a result of lopsided policies, for example, of plantation economies or colonisation schemes in the case of Sri Lanka; (4) The last but not least is the most important link between poverty and malaria or disease in general. The poor and socially marginalised sections have always been the worst affected. Therefore, without poverty alleviation, social justice and equity - transcending class, ethnic, gender and other barriers - there will be no sustainable malaria eradication.

The traditional malariology, as Turnbull (2000) has defined, investigates "interaction between three factors: the human host, the mosquito vector and malaria parasite manifested in a particular locale and time."

Kalinga Tudor Silva undoubtedly expands these premises at least on the side of the 'human host,' taking into account social history, power politics, policy interventions and presence or absence of social movements. This book is a substantive contribution to our human knowledge on the subject.

\section{REFERENCES}

Barry, A. \& Yuill, C. (2002) Understanding health: a sociological introduction, London: Sage.

David A. (1993) Colonizing the body, Berkley: University of California Press.

Marcus, B. (2004) Deadly diseases and epidemics, New York: Chelsea publications.

McNeill, W. (2008) People and plagues, Chicago: Paw Prints.

Nicholls, L. (1921) Malaria and the Lost Cities of Ceylon, Indian Medical Gazette (56).

Silva, K. T., Navaratna, H., Rao, M. A., Wanninayaka, P., Doolwala, S., Karunaratna, N., Manike, P. S., Gunathilaka, M. W. \& Dissanayaka, K. (1988) Malaria control through community action at the grass-roots: experience of the Sarvodaya malaria control research project in Sri Lanka from 1980 to 1986, Geneva: TDR.

Tennent, E. J. (1860) Ceylon: an account of the island, physical, historical and topographical with notices of its natural history, antiquities and productions, London: Longman. 
Turnbull, D. (2000) Masons, tricksters and cartographers: comparative studies in sociology, Amsterdam: Harwood Publishers.

Uragoda, C. G. A. (1987) History of medicine in Sri Lanka: from earliest times to 1948, Colombo: Sri Lanka Medical Association, pp: 221
Vijayawardhana, D. C. (1953) The revolt in the temple, Colombo: Sinha Publications.

Wilson, T. (1858) An inquiry into the origin and intimate nature of malaria, London: Henry Renshaw. 